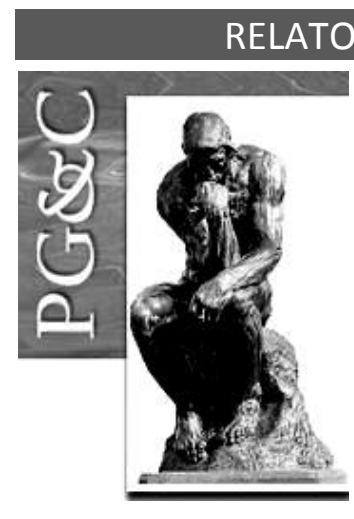

\title{
MECANISMOS DE TRANSFERÊNCIA DE CONHECIMENTO COM FOCO EM ECOINOVAÇÃO: UM ESTUDO CASO EM UMA EMPRESA AGROINDUSTRIAL
}

\author{
Marcelo Seido Nagano \\ Doutor em Engenharia Mecânica pela Universidade de São Paulo, Brasil. \\ Professor da Universidade de São Paulo, Brasil. \\ E-mail: drnagano@usp.br \\ Antonio lacono \\ Doutor em Engenharia de Produção pela Universidade de São Paulo, \\ Brasil. Professor da Universidade de São Paulo, Brasil. \\ E-mail: prof.antonioiacono@gmail.com \\ Lígia Maria Moura Madeira \\ Mestre em Engenharia de Produção pela Universidade de São Paulo, \\ Brasil. \\ E-mail: ligiamariamadeira@yahoo.com.br \\ Aldo Roberto Ometto \\ Doutor em Engenharia Hidráulica e Saneamento pela Universidade de São \\ Paulo, Brasil. Professor da Universidade de São Paulo, Brasil. \\ E-mail: aometto@sc.usp.br
}

\begin{abstract}
Resumo
Este artigo tem por objetivo investigar a ligação entre elementos do processo de gestão do conhecimento, representados pelos mecanismos de conversão, e os elementos relacionados ao processo de criação de conhecimento para a geração de ecoinovações. Para alcançar tais objetivos realizou-se um estudo exploratório, de abordagem qualitativa junto a uma empresa agroindustrial de grande porte, voltada à pesquisa, e de capital nacional. Os resultados revelam uma estreita ligação entre os mecanismos de conversão de conhecimento e as práticas e tarefas desempenhadas na P\&D para geração de ecoinovações. Os modos de conversão do conhecimento ocorrem em todos os projetos, tanto para a geração de ecoprocessos, quanto para a geração de eco-produtos inovadores. $O$ artigo contribui para uma melhor compreensão de como o conhecimento é criado e convertido para a geração de ecoinovações, identificando os principais mecanismos pelos quais a transferência de conhecimento ocorre.
\end{abstract}

Palavras-chave: Gestão do Conhecimento. Ecoinovação. Agroindústria.

\section{MECHANISMS OF KNOWLEDGE TRANSFER FOCUSED ON ECO-INNOVATION: A CASE STUDY IN AN AGRO-INDUSTRIAL COMPANY}

\begin{abstract}
This article aims to investigate the link between elements of the knowledge management process, represented by the conversion mechanisms, and the elements related to the knowledge creation process for the generation of eco-innovations. To achieve these objectives, an exploratory study was carried out, with a qualitative approach, with a large Brazilian agribusiness company, focused on research. The
\end{abstract}

Perspectivas em Gestão \& Conhecimento, João Pessoa, v. 9, n. 1, p. 42-61, jan./abr. 2019.

DOI: http://dx.doi.org/10.21714/2236-417X2019v9n1p42

http://periodicos.ufpb.br/ojs2/index.php/pgc. ISSN: 2236-417X. Publicação sob Licença (cc) EY-NC-ND 
results show a close link between the mechanisms of knowledge conversion and the practices and tasks performed in $R \& D$ for the generation of eco-innovations. The modes of knowledge conversion occur in all projects, both for the generation of eco-processes, and for the generation of innovative eco-products. The article contributes to a better understanding of how knowledge is created and converted to the generation of eco-innovations, identifying the main mechanisms by which knowledge transfer takes place.

Keywords: Knowledge Management. Eco-innovation. Agrobusiness.

\section{INTRODUÇÃO}

A ecoinovação está baseada na produção de um bem ou em processo de produção, estrutura organizacional ou método de gestão que seja novo para determinado contexto, resultando na diminuição dos impactos ambientais, considerando todo o ciclo de vida deste bem (KEMP; PEARSON, 2008). Segundo O'Hare, McAloone, Pigosso e Howard (2014), a ecoinovação pode ser observada quando uma empresa possui um perfil estratégico cujo caráter é inovador, em termos de agregar os princípios da sustentabilidade às suas operações. Esse novo perfil estratégico demanda um aporte por aspectos fundamentais, como: a colaboração em parceria na cadeia de valor e a visão do ciclo de vida. Toda esta arquitetura exerce uma influência positiva no desempenho das empresas, tanto em nível de soluções tecnológicas (processos e produtos), quanto em nível de gestão institucional (novas metodologias, valores, governança). Reid e Miedzinski (2008) acrescentam ainda que a ecoinovação está baseada na criação de novos processos, produtos e procedimentos que possam satisfazer as necessidades humanas, a fim de melhorar a qualidade de vida, considerando o uso reduzido dos recursos naturais e a reduzida liberação de resíduos, com base no ciclo de vida do bem. Ainda, a ecoinovação não se limita a inovações em processos, produtos e novos métodos organizacionais, mas inovações nas estruturas institucionais e sociais (OECD, 2009 a,b), podendo integrar os desafios ambientais no âmbito corporativo em várias dimensões, em termos de escopo, objetivos e mecanismos que orientam (CASTIAUX, 2012). Para que uma empresa possa ser considerada ecoinovadora no seu processo de manufatura, ela tem de incorporar o conceito de sustentabilidade no seu processo de inovação, implementando melhorias, sejam elas radicais ou incrementais nos seus processos e produtos, ou até mesmo melhorias na própria estrutura organizacional, levando-se em conta a inclusão de novas formas de gestão neste processo (OMETTO; PERES; SAAVEDRA, 2012).

Os benefícios de uma ecoinovação, conforme enfatizados em Arundel e Kemp (2009), somente serão possíveis por intermédio de transformações nos princípios institucionais, assim como, as contrações dos impactos ambientais somente poderão ser possíveis mediante determinadas transformações no gerenciamento da empresa.

Diante disso, é de suma importância uma análise mais aprofundada da trajetória do conhecimento que flui no interior das empresas no que diz respeito ao seu arranjo, processamento e sistematização em ecoinovação, bem como das técnicas e atividades empregadas nestes contextos, principalmente nos seus estágios anteriores.

Consoante a este fato, a trajetória que une os processos de conhecimento nas empresas e a aprendizagem organizacional para ecoinovação ainda não foi integralmente desvendada. O objetivo deste artigo, deste modo, é, identificar os mecanismos (meios) de transferência de conhecimentos para estes contextos, apresentando o modo como são influenciados na trajetória para novas criações. Para esta tarefa serão utilizadas práticas de gestão do conhecimento (GC), uma vez que cumprem o papel de facilitadoras do processo de conversão de conhecimentos essencial para novas criações.

Perspectivas em Gestão \& Conhecimento, João Pessoa, v. 9, n. 1, p. 42-61, jan./abr. 2019. 
Sendo assim, tomando-se como base o modelo SECI de Nonaka e Konno (1998), o presente trabalho tem por objetivo compreender como os modos de conversão de conhecimentos contribuem para a construção da ecoinovação. Para isso, foi realizado um estudo de caso em uma empresa do setor agroindustrial.

Este artigo está organizado em quatro seções, além desta introdutória: a seção 2 apresenta um referencial teórico sobre econinovação e gestão do conhecimento. A seção seguinte apresenta algumas considerações sobre os procedimentos metodológicos utilizados para a pesquisa de campo. Na seção 4, são apresentados os resultados da pesquisa de campo. Por fim, a última seção reúne as considerações finais, as limitações do estudo e as propostas para pesquisas futuras.

\section{FUNDAMENTAÇÃO TEÓRICA}

\subsection{Ecoinovação: contexto e definição}

O modo pelo qual as empresas integram as considerações ou preocupações ambientais na sua estratégia, enquanto consolidam as suas vantagens competitivas, é por meio das ecoinovações. Apesar do interesse no assunto ser crescente, as pesquisas neste campo são ainda limitadas. Porter e Linde (1995) e Rennings (2000) afirmam que as ecoinovações diferem de outras inovações na medida em que as externalidades e os motivadores para sua introdução estão envolvidos, realçando principalmente a importância das regulações para desencadeá-las.

Em termos gerais, a ecoinovação pode ser definida como os processos, técnicas, práticas, sistemas e produtos que são novos ou modificados, e que evitam ou reduzem os danos ambientais (BEISE E RENNINGS, 2005). Nesta definição estão inclusas todas as mudanças no portfólio do produto ou nos processos de produção que enfrentam as metas de sustentabilidade, como a gestão de resíduos, a ecoeficiência, a redução de emissões, a reciclagem, o ecodesign, ou qualquer outra ação implementada pelas empresas para reduzir a sua pegada ecológica (ecological footprint).

De acordo com a OECD (2009) a ecoinovação é uma inovação cujo conceito reflete explicitamente a ênfase na redução dos impactos ambientais, sejam estes intencionados ou não; e em segundo lugar, não é limitada a inovações em produtos, processos, e métodos organizacionais, mas também inclui a inovação nas estruturas sociais e institucionais. Segundo Castiaux (2012), as inovações sustentáveis são inovações que integram os desafios ambientais em vários graus, em termos de escopo, objetivos e mecanismos ou meios.

Vale destacar que, Segundo Kemp e Pearson (2008), o fato de uma tecnologia, produto ou serviço possuir um desempenho ambiental satisfatório não necessariamente fará com que sejam consideradas inovações ambientais. E é exatamente neste ponto que deve entrar a Avaliação do Ciclo de Vida. É importante que sejam analisados o ciclo de vida do produto, bem como toda a sua cadeia de produção, uma vez que muitos produtos podem ser considerados sustentáveis, mas que, no entanto, quando uma análise mais global de sua cadeia de produção é realizada, os benefícios da sua utilização podem ser anulados.

Triguero et al. (2013) estabelecem que, a ecoinovação é influenciada em cerca de $90 \%$ pelas capacidades tecnológicas e gerenciais das empresas, e ainda, por uma boa acessibilidade a fontes de conhecimentos externas, sejam estas tangíveis ou intangíveis, aliados às competências dos gestores e demais colaboradores, assim como do conhecimento técnico obtido de fontes externas.

Deste modo, com base em Rennings (1998), Maçaneiro e Cunha (2010) classificam as ecoinovações, quanto ao âmbito ou contexto de mudança, em quatro tipos: tecnológico, organizacional, sociais e institucionais, conforme definidos no Quadro 1.

Perspectivas em Gestão \& Conhecimento, João Pessoa, v. 9, n. 1, p. 42-61, jan./abr. 2019. 
Quadro 1 - Ecoinovações quanto ao contexto de mudança

\begin{tabular}{|l|l|}
\hline Tipos de Ecoinovações & \multicolumn{1}{c|}{ Caracterização } \\
\hline Tecnológicas & $\begin{array}{l}\text { Incluem Tecnologias que reparam danos: } \\
\text { a) tecnologias de fim de tubo, utilizadas após a produção e o processo de } \\
\text { consumo- end-of-pipe; } \\
\text { b) tecnologias limpas, que tratam as causas das emissões, durante o processo } \\
\text { de produção, ou no nível de produto. }\end{array}$ \\
\hline Organizacionais & $\begin{array}{l}\text { São mudanças nos instrumentos de gestão da empresa. A inserção de } \\
\text { ecoauditorias; ou a inovação em serviços (gestão da demanda de energia, } \\
\text { gestão do transporte de resíduos). Requer uma mudança na infraestrutura. }\end{array}$ \\
\hline Sociais & Mudanças nos valores e um padrão de consumo sustentável. \\
\hline Institucionais & São respostas institucionais inovadoras para a sustentabilidade ambiental. \\
\hline
\end{tabular}

Fonte: Elaborado a partir de Rennings (1998)

De acordo com Reid e Miedzinski (2008), as ecoinovações podem ser entendidas e analisadas em termos de suas metas, mecanismos e impactos (Quadro 2).

Quadro 2 - Elementos da ecoinovação

\begin{tabular}{|c|c|}
\hline $\begin{array}{l}\text { Elementos da } \\
\text { Ecoinovação }\end{array}$ & Caracterização \\
\hline $\begin{array}{l}\text { Objetivos ou metas: } \\
\text { Refere-se ao foco } \\
\text { básico da ecoinovação }\end{array}$ & $\begin{array}{l}\text { Produtos: envolve bens e serviços; Processos: métodos de produção ou } \\
\text { procedimentos; Métodos de Marketing: para promover e precificar os } \\
\text { produtos, entre outras estratégias orientadas pelo marketing; Organizações: } \\
\text { estrutura de gestão e a distribuição de responsabilidades; Instituições: } \\
\text { incluem arranjos institucionais, normas sociais e valores culturais. }\end{array}$ \\
\hline $\begin{array}{l}\text { Mecanismos: } \\
\text { Refere-se ao meio pelo } \\
\text { qual a ecoinovação } \\
\text { pretende ser } \\
\text { introduzida }\end{array}$ & $\begin{array}{l}\text { Modificações: ajustes pequenos, progressivos em processos e produtos; } \\
\text { Redesenho: refere-se a mudanças significativas nos produtos existentes, } \\
\text { processos, estruturas organizacionais; Alternativos: são bens e serviços que } \\
\text { possam preencher a mesma necessidade funcional e operar como } \\
\text { substitutos para outros produtos; Criação: é o desenho e a introdução de } \\
\text { todos os novos produtos, processos, procedimentos, organizações e } \\
\text { instituições. }\end{array}$ \\
\hline Impactos & $\begin{array}{l}\text { O impacto depende da combinação dos objetivos das inovações e } \\
\text { mecanismos. Refere-se ao impacto das ecoinovações no meio ambiente. }\end{array}$ \\
\hline
\end{tabular}

Fonte: Elaborado a partir de Reid e Miedzinski (2008)

Vale enfatizar que, as ecoinovações, em sua grande maioria, referem-se a mudanças em nível tecnológico, ou seja, devem ser analisadas quanto ao seu foco ou propósito de mudança (processos, produtos, métodos de gestão), quanto ao meio pelo qual ela pretende ser implementada (redesenho, ou algo totalmente novo), e ainda, quanto aos impactos que pode vir a causar no meio ambiente.

\subsection{Gestão do Conhecimento e a Integração com a Inovação}

A partir da década de 2000, constatou-se uma elevação da integração de processos de produção mais limpos no âmbito corporativo, assim como notou-se um aumento do interesse político envolvendo a questão da inovação nas questões ambientais (ANDERSEN, 2008). Belin et al. (2009), Hellström (2007) e Kemp e Pearson (2008) partilham da mesma afirmação 
quando estabelecem que, as empresas quando arquitetam seus processos de manufatura, incitam uma oportunidade para inovar, outorgando primazia aos atributos da sustentabilidade.

Uma boa gestão das competências organizacionais são fatores chave para que esse processo possa ocorrer, entretanto, ainda constitui uma lacuna, a compreensão de como o conhecimento pode ser combinado e convertido em contextos ecoinovadores.

Nonaka (1991) argumenta que as empresas expõem interiormente uma série de formas para transferir e compartilhar seus conhecimentos. As práticas de gestão do conhecimento podem auxiliar neste contexto, sendo assimiladas e internalizadas como mecanismos de transferência. Deste modo, é de grande importância e contribuição identificar os mecanismos de transferência de conhecimentos que envolvem o trabalho tanto da gestão quanto dos demais colaboradores, apresentando o modo como os conhecimentos para as operações podem ser agrupados, combinados e processados para novas criações em contextos ecoinovadores.

Armbrecht et al. (2001) apresentam três pilares que apoiam a gestão do conhecimento no P\&D, a saber: (i) cultura organizacional; (ii) infraestrutura organizacional; e (iii) tecnologia. De outra forma, Nonaka e Takeuchi (1997) estabelecem que a produção de novos conhecimentos nas empresas constitui-se de quatro fases de conversão, a saber: Socialização; Externalização; Combinação; e Internalização - SECl. As referidas fases são representadas na Figura 1:

Figura 1 - Modelo de Conversão de Conhecimento

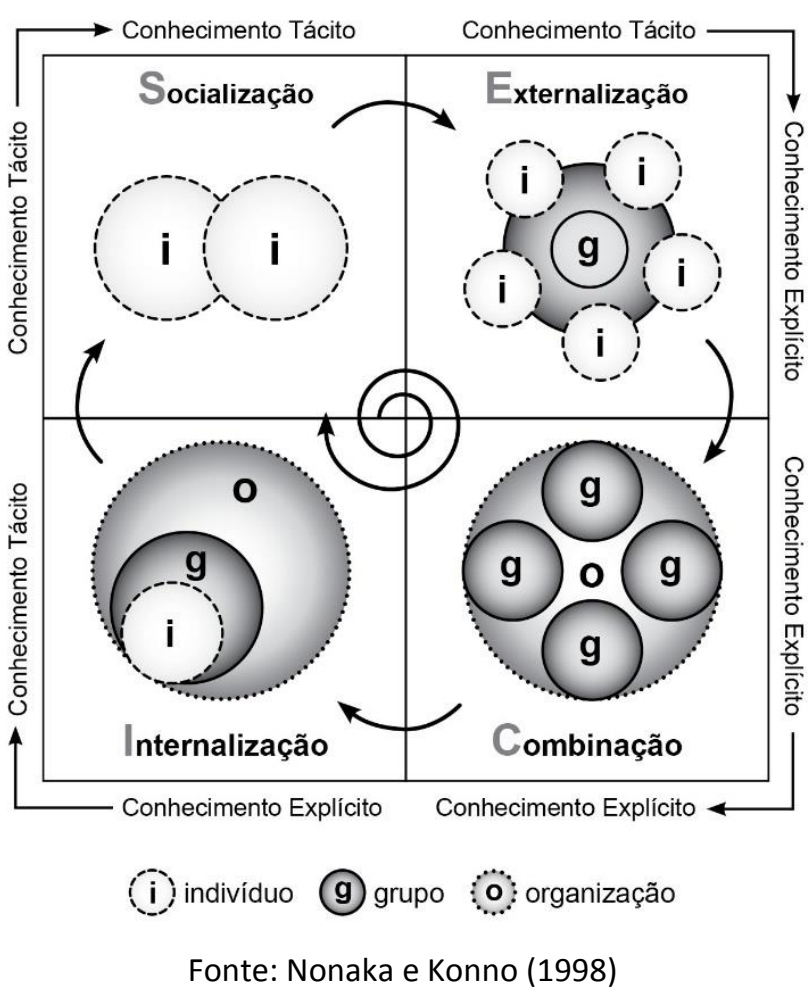

O modelo de conversão do conhecimento, representado pela espiral de criação de conhecimento $(\mathrm{SECl})$, é aplicável nos processos de inovação. Por meio das quatro formas de interação entre o conhecimento tácito e o conhecimento explícito, as empresas podem criar e gerenciar seus conhecimentos para que estes sejam inclusos aos novos processos e produtos.

Perspectivas em Gestão \& Conhecimento, João Pessoa, v. 9, n. 1, p. 42-61, jan./abr. 2019. 
A espiral de criação do conhecimento tem início com a Socialização, processo de conversão de conhecimentos tácitos por meio de experiências compartilhadas nas interações sociais e técnicas. É transferido e compartilhado mediante interações indivíduo a indivíduo.

Desta forma, este conhecimento individual passa a ser compartilhado em grupo, por meio da Externalização, tornando-se explícito e compondo a base conceitual para produção de novos conhecimentos na forma de imagens e documentos.

Após a fase de Externalização, segue-se o processo de Combinação, que consiste na reunião, edição e processamento de conhecimentos explícitos gerando conhecimentos explícitos mais complexos que serão difundidos pela empresa. A sistematização e a aplicação dos conhecimentos explícitos e das informações, portanto, podem ser realizadas por meio do recolhimento e integração, assim como da transferência e difusão do conhecimento explícito.

Por fim, no processo de Internalização, o conhecimento explícito, materializado, é aplicado, usado em experiências práticas e compõe a base cognitiva para novos processos. Portanto, a aprendizagem e a aquisição de novos conhecimentos tácitos na prática podem ser realizadas por meio da incorporação de conhecimento explícito por meio de ações e práticas, assim como de usos, simulações e experiências.

Vale ressaltar que neste processo há necessidade de uma capacidade e comprometimento dos indivíduos em querer criar, compartilhar e transferir os conhecimentos que retêm. Sem essa habilidade de compartilhamento e criação de conhecimento, torna-se muito difícil entre os indivíduos essa troca de conhecimentos entre si e com a empresa.

O P\&D é um dos contextos base para a criação de conhecimentos nas empresas. É o contexto em que é mais presumível a transmissão de procedimentos de distribuição de conhecimentos para outros espaços da empresa (DEMIREL E KESIDOU, 2011; ELMQUIST; SEGRESTIN, 2009; PUJARI, 2006). Neste contexto, as ideias e os projetos são trabalhados em conjunto, formando uma espécie de rede de colaboração. Diversos tipos de atividades ocorrem no seu domínio: atividades de projeto, administrativas, organizacionais e de gestão. Segundo Malmborg (2007), a colaboração interorganizacional em rede e as associações são elementos do P\&D. De acordo com Brännback (2003), o P\&D é o contexto que torna possível a transferência de tecnologia e a colaboração. Cainelli et al. (2011) e Wagner (2009) afirmam que as inovações ambientais podem ser criadas mediante a subsistência dos artifícios para partilhar conhecimentos e da envoltura em redes, o que somente confirma a assertividade do P\&D no cumprimento do seu papel. Tanto as atividades mais convencionais, mais institucionais, quanto as atividades mais simples, mais coloquiais são significativas para o P\&D (KHURANA; ROSENTHAL, 1997, 1998).

A inovação para a sustentabilidade requer uma rede ampla e variada, multidisciplinar de colaboradores, e isso inclui uma solicitude a mais com este processo, no que diz respeito ao incitamento de conceber, arquitetar um ambiente psicologicamente seguro e firme entre os colaboradores, e onde a confiança e o apoio devem predominar, respaldando que os colaboradores se sintam assegurados, resguardados, sendo determinados, confiantes e fidedignos na execução de suas atividades. Em razão disto, coloca-se como substancial o comprometimento para com o processo de inovação, notando-se o impasse entre a partilha e a propriedade sobre os conhecimentos, conhecido o superior sortimento do grupo de trabalho em termos de funções (KLEEF; ROOME, 2007).

\subsection{A Criação de Conhecimento em Contextos Ecoinovadores}

A gestão do conhecimento pode ser adotada por todo o P\&D, sendo este orientado particularmente para as questões ambientais ou não. Seus estágios iniciais podem ser notoriamente designados como um ciclo fundamental, como o alicerce para a performance das práticas de gestão do conhecimento, agregando um vasto curso de conhecimentos

Perspectivas em Gestão \& Conhecimento, João Pessoa, v. 9, n. 1, p. 42-61, jan./abr. 2019. 
variados e expressivos para as atividades. Considerando a ecoinovação, estes estágios iniciais podem ser entendidos como front end de ecoinovação - FEEI, podendo ser afirmados pela geração de ideias, pela identificação de oportunidades e pelo desenvolvimento de conceitos, discriminando-se do front end das inovações tradicionais, no sentido que, certos conhecimentos particulares, singulares e mecanismos são necessários para ocupar-se com as questões ambientais (BOCKEN et al., 2014).

É no front end de ecoinovação que se inicia, portanto, o processo de criação, no qual as ideias e informações devem ser arranjadas, agrupadas, combinadas e processadas, de modo que o processo de inovação alcance progresso e êxito.

A gestão do conhecimento, de acordo com Nonaka e Takeuchi (1997), oferece um bom direcionamento ao front end no sentido de delimitação e aplicação de suas práticas, aprimorando e melhorando seus estágios a princípio, e oferecendo-lhe sustentação, atuando deste modo como aporte na execução de suas atividades.

O front end, por sua vez, reúne as atividades retratadas como menos convencionais, menos institucionais, menos formais, podendo ser caracterizado como um estágio ainda não devidamente arquitetado. Em razão disto, justifica-se o fato que as atividades possam ser arranjadas e mescladas para o cumprimento de uma determinada finalidade (KHURANA; ROSENTHAL, 1997, 1998).

As práticas de gestão do conhecimento auxiliam, portanto, para que o conhecimento flua livremente pela empresa, agregando valor aos processos e propiciando tomadas de decisões mais precisas. A gestão do conhecimento deve entrar neste contexto agindo como uma estratégia para impulsionar as ecoinovações (DORAN; RYAN, 2012). Huang e Shih (2009, 2010) ressaltam a necessidade de haver um processo de gestão do conhecimento ambiental dentro da empresa a fim de estabelecer um relacionamento com as questões ambientais, e de se obter melhorias no fluxo de conhecimento necessário às atividades (WERNICK, 2003).

Figura 2 - P\&D Ambiental

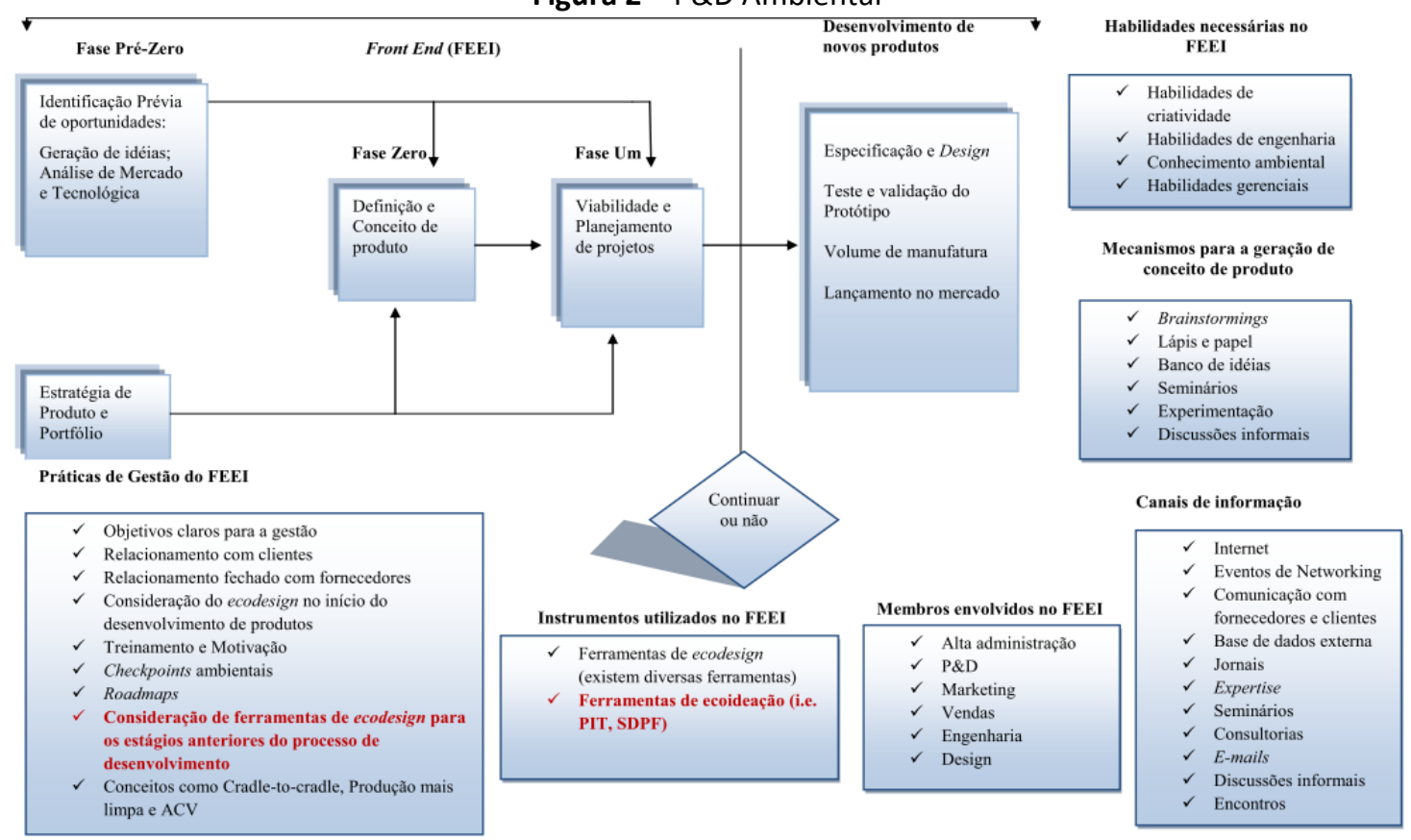

Fonte: Adaptado de Khurana e Rosenthal $(1997,1998)$ e Bocken et al. (2014)

A literatura apresenta alguns modelos de front end dentre os quais destaca-se os de Cooper (1988), Khurana e Rosenthal (1997; 1998), Koen et al. (2001; 2002), Flynn et al. (2003),

Perspectivas em Gestão \& Conhecimento, João Pessoa, v. 9, n. 1, p. 42-61, jan./abr. 2019. 
Boeddrich (2004), Whitney (2007). Para os propósitos deste trabalho o que mais se adequa à incorporação das considerações ambientais é o de Khurana e Rosenthal $(1997,1998)$. Tal modelo de front end é composto por três fases e com dois grupos de atividades compostas por elementos de fundação e elementos específicos dos projetos (Figura 2). Os elementos de fundação são aqueles que não fazem parte direta do desenvolvimento de novos produtos, mas direcionam todo o processo: estratégia do produto, planejamento do portfólio de produtos, estrutura organizacional de desenvolvimento de produtos. 0 segundo grupo de atividades corresponde ao conceito e definição do produto, considerações da cadeia de valor, definição e planejamento do projeto no front end.

As referidas três fases, são: (i) Pré-fase zero: São identificadas oportunidades por meio de análise de mercado e de tecnologia; (ii) Fase zero: É definido o conceito de produto; e (iii) Fase um: Realiza a definição do produto e planeja o seu projeto.

Nesse contexto, torna-se crucial a compreensão de como os ecoinovadores realizam o estágio inicial dos projetos de ecoinovação, que levam a avanços em direção à sustentabilidade ambiental, ou seja, compreender quais os mecanismos organizacionais, ferramentas, atividades e técnicas empregadas nos projetos de inovação, que permitem que a inovação específica ambiental surja e tenha aceitação, em particular, nos estágios iniciais do processo de inovação.

Para Bocken et al., 2014, as dimensões a serem analisadas para o front end de ecoinovação compreendem: (a) práticas de gestão; (b) tipos habilidades; (c) ferramentas; (d) membros envolvidos; (e) canais de informação; e (f) mecanismos para a geração de conceito de produto, conforme mostradas na Figura 2.

As práticas de gestão buscam compreender como é o gerenciamento eficaz da FEEl; Identificar os fatores que contribuem para a integração bem-sucedida do design ecológico no desenvolvimento de produtos. São exemplos que integram aas práticas de gestão 0 estabelecimento de metas claras; relações com o consumidor; relações com fornecedores; consideração do ecodesign no início do desenvolvimento do produto; treinamento e motivação, dentre outros. Da mesma maneira, é importante o comprometimento da alta gerência para a integração da sustentabilidade no desenvolvimento de novos produtos. Além disso, as metas de sustentabilidade precisam ser integradas no resumo do projeto; o treinamento e a educação regulares também são necessários, pois podem encorajar o uso de ferramentas de ecodesign, bem como a cooperação entre diferentes áreas funcionais, como design e marketing. Vale destacar também a diversidade de equipes, que pode contribuir para a criatividade se bem gerida (BOCKEN et al., 2014). Em especial, as ferramentas de ecodesign se destacam por integrarem questões ambientais no desenvolvimento de produtos, e por serem ferramentas que podem ser aplicadas na orientação, avaliação, comparação, trade-off e ecoideação.

Pela Figura 2 é possível observar a relevância das tarefas e práticas ligadas à gestão dos diversos conhecimentos organizacionais no P\&D das empresas, tanto no front end quanto no processo de desenvolvimento de produtos, representando, portanto, a necessidade de alinhamento destas práticas por meio do processo de conversão do conhecimento, para que possam ser compreendidas e difundidas efetivamente como mecanismos de transferência de conhecimento para a construção das ecoinovações.

Khurana e Rosenthal (1998) enfatizam a importância do alinhamento do front end com as estratégias de produto e portfólio. A Figura 2 mostra o P\&D voltado para sustentabilidade ambiental (i.e. P\&D Ambiental), subdividido entre $\mathrm{o}$ front end $\mathrm{e} o$ processo de desenvolvimento de novos produtos. 


\section{PROCEDIMENTOS METODOLÓGICOS}

Esta pesquisa, realizada em 2014, tem como propósito investigar a ligação entre elementos do processo de gestão do conhecimento, que são os modos de conversão do conhecimento e os elementos relacionados ao processo de criação de conhecimento no P\&D para a geração de ecoinovações, que são as práticas e tarefas de gestão do conhecimento desempenhadas no P\&D para a gerá-las.

Para alcançar tais objetivos, a pesquisa foi dividida em duas etapas principais. A primeira dedicou-se ao levantamento bibliográfico dos conceitos ligados aos temas de pesquisa: processo de ecoinovação e gestão do conhecimento. A segunda parte constituiu-se de uma pesquisa de campo exploratória. $O$ estudo de caso foi o método de investigação utilizado para a exploração dos dados. A escolha deste método de investigação foi devido a necessidade de maior exploração empírica e aprofundamento sobre aspectos ligados à gestão do conhecimento no processo de geração de ecoinovações.

De acordo com Yin (2005), o estudo de caso como método de investigação exploratória é adequado para estudos que abordam temas recentes ou que ainda foram pouco explorados. A abordagem empregada nesta pesquisa é, portanto, qualitativa, reconhecendo que existe uma relação dinâmica entre o mundo real e o sujeito.

A natureza qualitativa caracteriza-se por ser descritiva, uma vez que retrata a realidade; e por considerar o ambiente sua fonte de coleta de dados, e o pesquisador seu instrumento-chave. Ao se adotar a abordagem qualitativa, o foco recai na trajetória percorrida, e não simplesmente nos resultados. Isto permite o aprofundamento no contexto e nas especificidades do caso.

\subsection{Escolha do caso}

O presente estudo de caso optou por uma empresa de grande porte, localizada no estado de São Paulo, vinculada ao Ministério da Agricultura, Pecuária e Abastecimento. Possui um centro de pesquisa, criado em 1984, atualmente com um quadro técnico de 87 colaboradores, entre assistentes, técnicos, analistas e pesquisadores. A equipe é interdisciplinar formada por engenheiros eletrônicos, mecânicos, de materiais, físicos e bioquímicos. Sua escolha deve-se por ser uma instituição de pesquisa, desenvolvimento e inovação (PD\&I), voltada para a geração de conhecimento, no caso, para a agroindústria. A geração de produtos da empresa é condizente com os fins desta pesquisa, advindos da nanotecnologia e da agroenergia. Além destas, destacam-se linhas de pesquisas relacionadas à agricultura de precisão, manejo e conservação do solo e da água, e meio ambiente.

A empresa desenvolve PD\&I voltadas a novas tecnologias e processos para produção e agroindustrialização de alimentos seguros, diversificados e nutritivos. Também fazem parte 0 desenvolvimento em balanço energético, balanço de carbono, estudos de ciclo de vida e oportunidades de mecanismo de desenvolvimento limpo, considerando as características de cada bioma.

Possui um centro de pesquisa há mais de 30 anos e um quadro técnico de 87 colaboradores, entre assistentes, técnicos, analistas e pesquisadores. Fazem parte do quadro interdisciplinar profissionais como engenheiros eletrônicos, mecânicos e de materiais, físicos e bioquímicos, que trabalham de maneira integrada com agrônomos, veterinários, biólogos, e com profissionais do Sistema Nacional de Pesquisa Agropecuária (SNPA).

O desenvolvimento propriamente dito ocorre na área de P\&D; e todos os projetos da empresa são vinculados à área de sustentabilidade, e, portanto, a questão ambiental está fortemente presente em seus projetos. A empresa possui parcerias com várias universidades brasileiras e outras instituições da Europa e Estados Unidos.

Perspectivas em Gestão \& Conhecimento, João Pessoa, v. 9, n. 1, p. 42-61, jan./abr. 2019. 


\subsection{Coleta e análise de dados}

De acordo com Yin (2005), a utilização de múltiplos instrumentos de coleta de dados possibilita a obtenção de resultados mais robustos. Em especial, esta pesquisa fez uso de dois instrumentos de coleta de dados, a análise documental e as entrevistas.

A análise documental foi realizada em registros impressos e digital. Teve por objetivo avaliar as políticas internas da empresa e os sistemas de gestão e processos.

No caso das entrevistas, inicialmente foi solicitada uma autorização, por meio de um ofício encaminhado à empresa, explicitando o propósito da pesquisa e a necessidade de contato com um especialista.

A análise dos dados foi realizada por meio de um roteiro de referência de entrevista, organizadas em dois blocos, onde participaram gestores pertencentes à área de supervisão estratégica de sustentabilidade, chefia adjunta de P\&D, chefia adjunta de administração e gerência de prospeç̧ão tecnológica.

O primeiro bloco teve por objetivo analisar (i) os projetos específicos com foco em ecoinovação; (ii) a geração de ideias; e (iii) a difusão de ideias.

No segundo bloco de questões foram exploradas as práticas de gestão de conhecimento presentes na empresa.

\subsection{Estrutura analítica da pesquisa}

A estrutura analítica utilizada para investigar a ligação entre elementos do processo de gestão do conhecimento e os elementos relacionados ao processo de criação de conhecimento para a geração de ecoinovações é composta de duas partes.

Uma primeira parte, representada pela Figura 3, relaciona as práticas de gestão do conhecimento para o apoio à ecoinovação, cuja nomenclatura está apoiada em Kuniyoshi (2008).

Figura 3 - Práticas de gestão do conhecimento para o apoio à ecoinovação

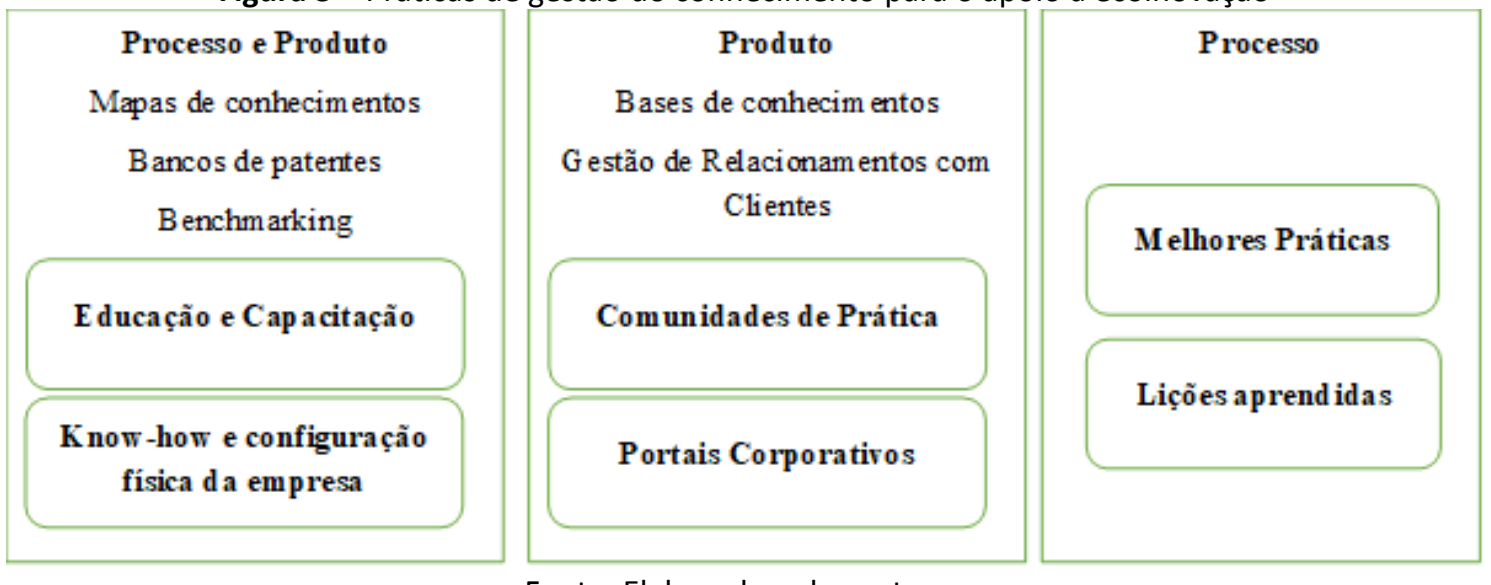

Fonte: Elaborado pelos autores

Uma breve descrição, de acordo com Kuniyoshi (2008), das referidas práticas é feita em seguida.

- Base de Conhecimentos: É uma estrutura organizada de informações, visando facilitar o armazenamento de conhecimentos, assim como a sua recuperação para aplicação nos processos de decisão e de trabalho.

Perspectivas em Gestão \& Conhecimento, João Pessoa, v. 9, n. 1, p. 42-61, jan./abr. 2019. 
- Benchmarking: É uma pesquisa acerca das melhores práticas do mercado, por meio das quais a empresa aprende um modo melhor de realizar algumas atividades, podendo adaptar estes métodos para a sua própria realidade.

- Melhores Práticas: É uma melhoria em processos, técnicas, que seja tão boa a ponto de ser capaz de substituir uma prática já existente. Ela pode deste modo, ser absorvida para replicação em situações semelhantes.

- Comunidades de Prática: Representam redes de informações multidisciplinar, permitindo o compartilhamento de conhecimentos, sendo apoiada pela TI.

- Lições Aprendidas: São conhecimentos resultantes da análise de um projeto.

- Mapas de Conhecimento: São mapas que indicam e relacionam fontes de conhecimento chaves para a empresa.

- Portal Corporativo: Integra informações personalizadas da empresa, facilitando o acesso às informações internas da empresa. As comunidades virtuais e listas de discussões podem ser incorporadas a esta prática.

- Repositórios de Documentos: É um local para armazenamento e recuperação do conhecimento explícito. As lições aprendidas e as melhores práticas podem ser incorporadas a esta prática.

Uma segunda parte, apoia-se nas fases de conversão do conhecimento individual para o conhecimento organizacional, mostradas no Quadro 3:

Quadro 3 - Fases de conversão do conhecimento individual para o organizacional

\begin{tabular}{|l|l|}
\hline \multicolumn{1}{|c|}{ Fases } & \multicolumn{1}{c|}{ Descrição da fase } \\
\hline Socialização & $\begin{array}{l}\text { Fase inicial constituída pelo conhecimento tácito (individual, subjetivo), sendo } \\
\text { transferido e compartilhado mediante interações pessoa a pessoa. }\end{array}$ \\
\hline Externalização & $\begin{array}{l}\text { Fase em que o conhecimento tácito é convertido em conhecimento explícito, na } \\
\text { forma de imagens e documentos, sendo assimilado por um indivíduo ou pela } \\
\text { empresa para ser compartilhado. É neste momento que o novo conhecimento é } \\
\text { criado. }\end{array}$ \\
\hline Combinação & $\begin{array}{l}\text { Fase em que o conhecimento explícito é combinado e sistematizado, } \\
\text { representado, por exemplo em manuais, podendo ser assimilado e internalizado } \\
\text { globalmente pela empresa. }\end{array}$ \\
\hline Internalização & $\begin{array}{l}\text { Fase em que o conhecimento criado é convertido para a empresa. Ele é } \\
\text { transferido aos indivíduos, mediante a assimilação por meio de leitura, audição, } \\
\text { internalizando-os a princípio, para consequentemente incorporá-los às } \\
\text { atividades. }\end{array}$ \\
\hline
\end{tabular}

Fonte: Elaborado pelos autores a partir de Nonaka e Konno (1998)

\section{RESULTADOS}

\subsection{Práticas de Gestão do Conhecimento para o Apoio à Ecoinovação}

A implementação de inovações em eco-processos e em eco-produtos é vigorosamente movida pela capacidade tecnológica e gerencial das empresas, e motivada de modo relevante, tanto por ativos tangíveis quanto por ativos intangíveis. De maneira geral, as práticas que se destacaram no presente estudo de caso referem-se ao treinamento tanto por parte dos colaboradores em geral, quanto por parte dos gestores; e ao apoio de redes externas de conhecimentos (universidades e institutos de pesquisa, e fornecedores).

Uma análise mais detalhada dessas e de outras práticas identificadas nesta investigação são apresentadas a seguir.

Perspectivas em Gestão \& Conhecimento, João Pessoa, v. 9, n. 1, p. 42-61, jan./abr. 2019. 
As implementações foram auxiliadas por ações que contribuam para a capacitação dos colaboradores - coaching, mentoring, workshops, seminários, eventos, feiras; por um arcabouço que forneceu suporte na execução das atividades na empresa, balizados pelo knowhow e pela configuração física da corporação, incorporando os centros de pesquisa, as bases de competências específicas e as fontes de ideias.

Além destes dois pilares essenciais destaca-se um terceiro, o qual é constituído por um repertório de práticas de gestão do conhecimento capazes de armazenar uma ampla gama de dados, informações e conhecimentos necessários para a manutenção das mais diversas atividades. Nesta trajetória, portanto, os mapas de conhecimentos, dedicam-se ao mapeamento de pessoas, ao encontro dos especialistas certos para as funcionalidades. Já, a memória corporativa por sua vez atua como uma espécie de banco de dados, no qual os dados inseridos neste banco compreendem um grande conjunto de informações formadas por métodos, estratégias e aptidão para as atividades. E por último, o banco de patentes, uma importante fonte de armazenamento de tecnologias e produtos já criados. Cabe salientar ainda, que a ferramenta benchmarking atua com muita destreza no mapeamento e diagnóstico das mais diversas informações que se quer obter, auxiliando em grande medida em muitas tomadas de decisão.

Vale a pena dizer neste ponto, que para o caso pesquisado a capacitação recebe um grande incentivo por parte de toda a corporação, conforme será observado mais à frente. Do mesmo modo, as comunidades de prática, e consequentemente, os portais corporativos cumprem um grande papel no âmbito colaborativo para a troca e a transferência dos conhecimentos necessários. Sabe-se que o objetivo último e premente de toda a corporação é o cumprimento global de toda trajetória de aprendizagem organizacional, da melhor forma e com os recursos certos para tal.

As comunidades de prática são essenciais na constituição de um ambiente de trabalho fundamentado e estruturado com base na troca e na transferência de conhecimentos entre os colaboradores, e cuja essência é alicerçada no compartilhamento multidisciplinar de experiências e conhecimentos que quando unidos, concedem energia à corporação, cultivando, e aprimorando seus trabalhos em um ciclo constante. Na empresa, as comunidades de prática são envolvidas pela troca de experiências dos gestores, os quais compartilham seu know-how entre si, permeados pela discussão de temas e assuntos estratégicos.

Os portais corporativos por sua vez, possibilitam simultaneamente o acesso a conhecimentos específicos e a difusão de conhecimentos gerados, agindo como uma espécie de banco de dados aonde é possível agrupar e combinar conhecimentos para posteriormente acessá-los. Neste mesmo bloco de práticas, a base de conhecimentos incorpora a expertise para os projetos, e a gestão de relacionamento com clientes possibilita que a empresa possa trabalhar junto ao cliente, sendo este um fator muito importante para que seu produto seja reconhecido em termos de qualidade, aumentando as chances de êxito no mercado; é um canal aonde se pode ter um feedback dos clientes, o que auxilia em grande medida os colaboradores no seu ambiente de trabalho, assimilando o conhecimento obtido que foi mapeado, diagnosticado e internalizando, incorporando às novas criações.

Com base na categorização realizada e no cruzamento com os dados coletados, pressupõe-se que as práticas desta seção possam auxiliar em maior nível no âmbito das inovações em eco-produtos.

Por último, as práticas que podem auxiliar em maior nível no âmbito das inovações em eco-processos são de um lado, as melhores práticas, que são práticas cujo saber e conhecimento podem ser buscados fora do contexto interno da empresa, sendo assimiladas a princípio, para que posteriormente possam ser trazidas à empresa e incorporadas nas suas atividades, otimizando seu funcionamento e execução. Geralmente, estas melhores práticas são constituídas por novos métodos, novos procedimentos ou novas soluções para o trabalho,

Perspectivas em Gestão \& Conhecimento, João Pessoa, v. 9, n. 1, p. 42-61, jan./abr. 2019. 
contribuindo com melhorias no trabalho pré-existente. Por outro lado, as lições aprendidas atuam como uma espécie de banco de informações constituídas por trajetórias e passos de processos previamente executados, contribuindo no aspecto de não se ter que refazer certos procedimentos.

A Figura 4 foi elaborada com o intuito de fornecer uma visão esclarecida de que a gestão do conhecimento envolve toda a cadeia de valor, através de sua aplicação por meio dos colaboradores integralizados no ciclo de vida.

Figura 4 - Colaboração na cadeia de valor com base na abordagem de ciclo de vida

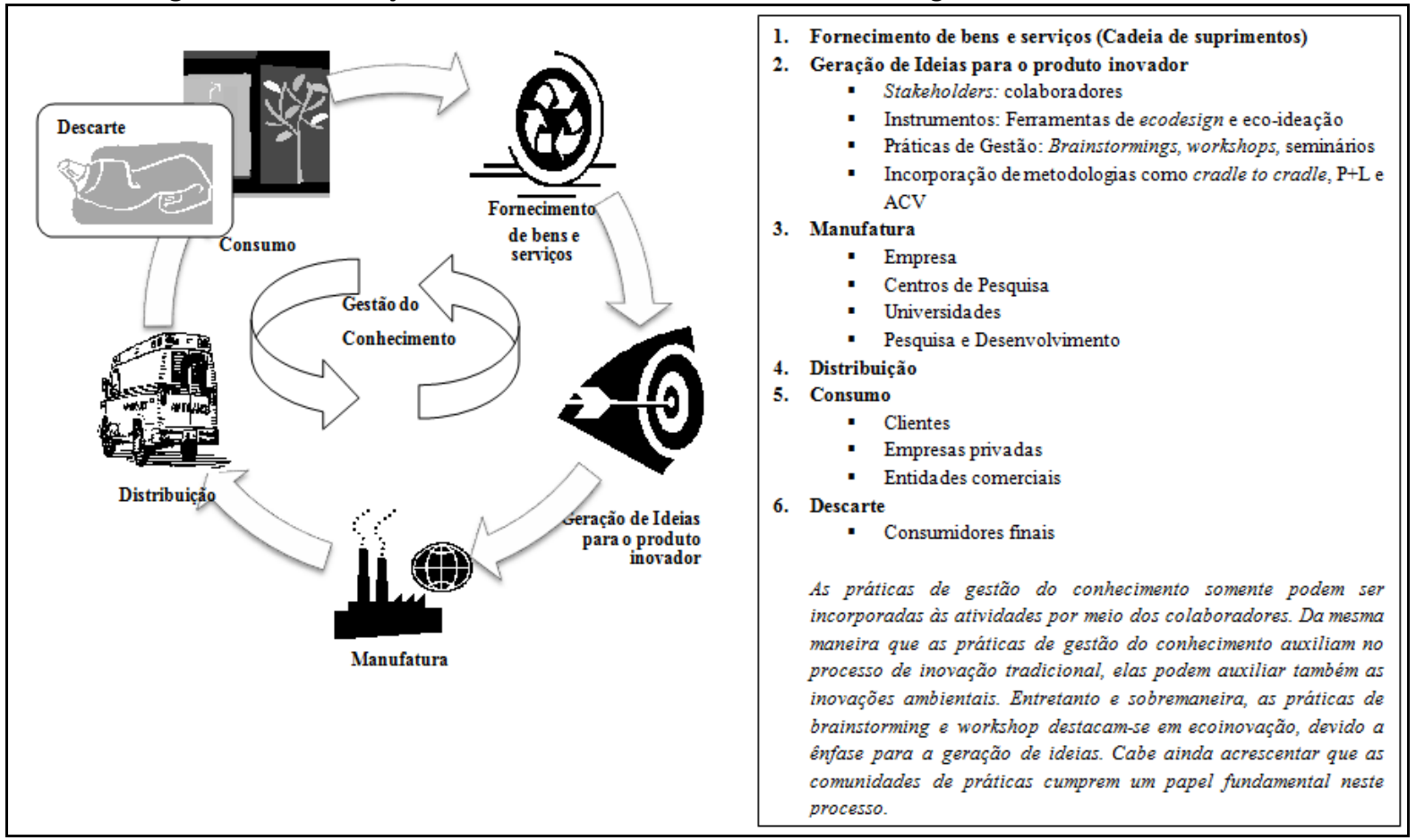

Fonte: Elaborado pelos autores a partir de pesquisa de campo

Alguns delineamentos podem ser distinguidos em termos de práticas de gestão do conhecimento, mediante a categorização realizada via análise de literatura pertinente, associados ao estudo de caso e à abordagem de ciclo de vida, com o intuito de oferecer uma gama de situações práticas de gestão que possam ser aplicadas pelos colaboradores (stakeholders) em suas atividades, sejam elas operacionais ou decisórias, considerando os três primeiros estágios do ciclo de vida, observados como fundamentais no que diz respeito a fornecer todo o embasamento necessário para que o processo de desenvolvimento de novos produtos inovadores possa ser bem sucedido e arquitetado da melhor forma.

Seguem-se situações práticas balizadas pela gestão do conhecimento que possam servir como aporte aos colaboradores em nível decisório e operacional na escolha da matériaprima; na geração de ideias para o produto inovador e no processo de manufatura:

- Pesquisas/consultas acerca de novas tecnologias podem ser efetuadas por intermédio de um banco de patentes, assim como por um efetivo benchmarking e pela gestão de relacionamento com clientes;

- Pesquisas acerca de informações chave como matéria-prima (material renovável, material reciclado) podem ser efetuadas em bases de conhecimentos e no portal corporativo da empresa;

- Os especialistas certos para as atividades podem ser encontrados por intermédio da memória corporativa e por mapas de conhecimentos; 
- Como infraestrutura e aporte ao trabalho, a empresa conta com o subsídio de sua configuração física e do know-how de seus colaboradores, assim como, Ihes oferece educação e capacitação por intermédio de seminários, eventos, feiras e workshops;

- As comunidades de prática devem ser úteis desde o início do processo, passando pelos três estágios do ciclo de vida, contribuindo para um efetivo compartilhamento de experiências;

- Nos dois estágios iniciais, considerando a visão do ciclo de vida, uma eficiente associação pode auxiliar na integralização de conceitos novos ao produto: brainstormings, a incorporação dos conceitos cradle-to-cradle, $\mathrm{P}+\mathrm{L}$ e ACV e as ferramentas de ecodesign e eco-ideação; na mesma trajetória, o supply chain estabelece um papel fundamental como stakeholder nestes estágios;

- Os colaboradores, as universidades, os institutos de pesquisa, são fundamentais desde o início do processo, representando os stakeholders envolvidos;

- O acesso a novas técnicas e novos procedimentos para o processo de manufatura podem ser angariados por intermédio da memória corporativa. Nesta mesma trajetória, as bases de conhecimentos possibilitam o acesso a informações chave, tais como a matéria-prima, os componentes e as técnicas;

- A busca por novas soluções tecnológicas, técnicas, procedimentos previamente executados, avalizados e que possam ser integralizados a um novo processo ou produto é possível por intermédio das melhores práticas;

- O aprendizado decorrente de práticas, como a citada anteriormente, de processos operacionais previamente executados que permitam que seus procedimentos possam ser utilizados em um novo processo de produção, advém das lições aprendidas;

- Os portais corporativos da empresa atuam como uma eficiente ferramenta de disseminação de informações chave, como por exemplo, as especificações de um produto, como a durabilidade e as características específicas funcionais (um menor consumo de energia ou que possibilite um consumo mais limpo, ou seja, que libere menos resíduos); ou informações que caracterizam o produto ou alguns de seus componentes que possam ser reciclados e posteriormente reutilizados;

- Os clientes exercem o papel de stakeholders chave nos dois estágios finais (consumo e descarte), considerando a visão do ciclo de vida.

Ainda, considerando a análise cruzada realizada com base nos dados da literatura e nos dados coletados para o Case, mais alguns delineamentos podem ser obtidos com o intuito de oferecer um aporte de situações práticas que possam auxiliar os colaboradores tanto em nível operacional quanto em nível decisório:

- Contextos formados por circunstâncias e premissas envolvendo o mapeamento de novos conhecimentos, técnicas, melhores práticas, contribuindo com a aprendizagem organizacional e obtendo proventos com lições aprendidas, incorporam possivelmente o âmbito das inovações em eco-processos;

- Contextos formados por circunstâncias e premissas envolvendo a criação de um ambiente de colaboração para o trabalho, permitindo o acesso a bancos de dados e à difusão de novos conhecimentos, incorporam possivelmente o âmbito das inovações em eco-produtos;

- A criação de conhecimento com foco no âmbito das inovações em eco-processos pode possivelmente ser auxiliada pela capacitação, por práticas que auxiliem a gestão na tomada de decisões por novos processamentos e opções tecnológicas, e

Perspectivas em Gestão \& Conhecimento, João Pessoa, v. 9, n. 1, p. 42-61, jan./abr. 2019. 
por práticas que permitam uma boa conexão com o ambiente empresarial que sustenta a aprendizagem;

- O estímulo às quatro formas ou fases de conversão de conhecimento ocorrem em ambos os contextos.

\subsection{A socialização e a externalização para compartilhamento de conhecimentos}

Os projetos na empresa são apoiados e fundamentados em um planejamento de grande porte ou macro-programas delimitado pelo governo, empenhando-se em uma composição em parcerias, entre governo, empresa e seus diversos stakeholders. A gestão do conhecimento atua neste contexto buscando competências, com o propósito de identificar uma rede de especialistas, agregando as pessoas e as suas aptidões singulares, de modo que se consiga apreender os indivíduos especializados para as atividades, considerando a elaboração do plano institucional.

Os projetos na empresa são mapeados, diagnosticados pela chefia de pesquisa de P\&D. A comunicação dos projetos na empresa, por parte dos pesquisadores, pode assinalar a prática do mentoring. Por outro lado, o ensejo facultado a alunos de pós-graduação e a iniciação científica denota a prática do coaching, na qual o aluno é inicialmente orientado, e na sequência avaliado, de acordo com os seus rendimentos.

A educação corporativa na empresa, representa uma oportunidade para que seus colaboradores possam atualizar seus conhecimentos, incorporando deste modo todo o arcabouço de conhecimentos necessário à capacitação e ao treinamento dos seus colaboradores, sendo retratada por convênios com universidades, por cursos online, e interunidades, podendo auxiliar por exemplo, na utilização de conhecimentos e metodologias distintos. Gavronski et al. (2012) ressaltam a importância da busca por fontes de conhecimentos externas, uma vez que apenas a troca de conhecimento interna não é capaz de fomentar a inovação, existindo deste modo a necessidade premente de parcerias e colaboração em rede para a implementação. Demonstram também que os gestores cumprem um papel fundamental neste processo de troca de conhecimentos externos; no estabelecimento de parcerias em rede; no relacionamento com fontes de conhecimentos estratégicas, como fornecedores e clientes, fomentando um ambiente de colaboração para o trabalho, e no longo prazo, criando valor por meio de novas criações.

Conforme mencionado, a empresa investe na atualização do conhecimento dos seus colaboradores, em participações em eventos, congressos internacionais, cabendo salientar que, os workshops são práticas muito relevantes para a transferência e compartilhamento de conhecimentos.

A comunidade de prática é uma prática de extrema relevância na empresa, pois promove um ambiente de colaboração. O papel e participação dos gestores é elementar. As reuniões na empresa são desenvolvidas em salas de gestores, sendo composta por uma equipe multidisciplinar aonde os integrantes discutem diversos temas. São disponibilizados deste modo, temas e assuntos importantes para a unidade e para o momento em questão. Todos os gestores são cadastrados, sendo que eles recebem e postam, depositam sugestões.

\subsection{A combinação e a internalização para compartilhamento de conhecimentos}

A aprendizagem organizacional na empresa se apresenta como uma concepção de eminente magnitude, uma vez que envolve todas as criações. As lições aprendidas são englobadas a um banco de boas práticas, sendo este disponibilizado para a unidade e interunidades, com o propósito de evitar a recriação de certos procedimentos que já foram

Perspectivas em Gestão \& Conhecimento, João Pessoa, v. 9, n. 1, p. 42-61, jan./abr. 2019. 
antemão empreendidos. Por outro lado, os relatórios que a empresa produz, em conformidade com os objetivos da administração e do P\&D podem designar as melhores práticas.

Seu portfólio, composto por variados conhecimentos, é formado por bases de conhecimentos, bases físicas de processos, produtos e tecnologias, evidenciando a sua memória corporativa, disponíveis nas formas física ou eletrônica, permitindo que o conhecimento possa ser combinado, agrupado, sendo consequentemente internalizado e assimilado pelos colaboradores para as atividades. Os e-mails fazem parte da fase de internalização, permitindo que os indivíduos possam assimilar conhecimentos ou informações por meio da sua leitura.

O benchmarking na empresa representa uma espécie de mapeamento ou diagnóstico, à medida em que são buscadas fontes de conhecimentos externas. Esta prática possibilita que os gestores, por exemplo, busquem novas opções tecnológicas, novas opções para o setor, e até mesmo, podem fortalecer o relacionamento com algumas fontes de conhecimentos estratégicas, como os fornecedores e clientes, sendo que a gestão de relacionamento em si permite uma espécie de busca neste sentido.

\section{CONSIDERAÇÕES FINAIS}

Pelos resultados foi possível identificar um conjunto de práticas que auxiliam no processo, obtendo-se alguns delineamentos, assim como uma categorização, facilitando a busca por este tipo de informações para a manutenção das implementações.

Considerando que a empresa é essencialmente voltada para pesquisa, o conhecimento passa a ser a estrutura, a base para o desenvolvimento de novos produtos e tecnologias. Conforme observado, muitas fontes de conhecimento são buscadas, sendo que a finalidade é simplesmente, que o conhecimento possa fluir tanto dentro da empresa, quanto interunidades, apresentando-se como uma oportunidade para que os seus colaboradores possam compartilhar seus conhecimentos, e consequentemente atualizá-los mediante as oportunidades de educação e treinamento oferecidas.

A gestão do conhecimento é uma prática que pode ser incorporada aos departamentos de Pesquisa \& Desenvolvimento por meio da união de competências, habilidades e conhecimentos, ou seja, da interação entre os recursos organizacionais, tendo como suporte um ambiente apoiador, sendo que a cooperação é um fator estritamente essencial nestes contextos em específico, a fim de que se possa desenvolver novas criações (produtos e tecnologias), como até mesmo aperfeiçoar as já existentes.

Conforme observado, algumas práticas são mais relevantes na unidade, refletindo-se deste modo no P\&D, como as comunidades de prática e o benchmarking. Nesta mesma trajetória, a aprendizagem organizacional, as bases de conhecimentos e os portais corporativos (repositórios de conhecimentos) também são práticas muito relevantes. Pela análise, tal fato já reflete que a empresa apresenta um foco maior para processos. Vale ainda ressaltar que essas práticas servem como aporte tanto para as inovações tradicionais quanto para as ecoinovações. Uma contribuição importante desta pesquisa recai na categorização concedida a inovações em processos e a produtos, mediante seu direcionamento em termos de ecoinovação, construída mediante inferências realizadas via análise de literatura pertinente e coleta de dados.

Observou-se que o estabelecimento de práticas de gestão do conhecimento deve ser baseado estritamente na construção de parcerias e a partir da identificação de oportunidades e desafios existentes no âmbito empresarial. Cada colaborador pode contribuir de algum modo para as atividades de ecoinovação. $O$ objetivo premente é o de identificar ferramentas, instrumentos e situações práticas que possam ser aplicadas via stakeholders por toda cadeia

Perspectivas em Gestão \& Conhecimento, João Pessoa, v. 9, n. 1, p. 42-61, jan./abr. 2019. 
de valor, contribuindo deste modo para as atividades de ecoinovação. Cabe ainda salientar que, em termos de ecoinovação os instrumentos que favorecem o processo de geração de ideias, como os workshops e o brainstorming recebem destaque importante. Em suma, a geração de ideias é um dos estágios chave do $P \& D$, capaz de influenciar globalmente toda a arquitetura do processo de inovação.

Consoante a integração da categorização à análise, acrescida da contextualização da gestão do conhecimento, pode ser inferido que: o benchmarking, a memória corporativa para mapear processos, as melhores práticas, o coaching, o mentoring, as lições aprendidas, e a educação corporativa, são práticas de gestão do conhecimento que podem vir a auxiliar em um maior nível de relevância na criação de conhecimento no âmbito das inovações em ecoprocessos. Cabe ainda salientar que, as comunidades de prática podem auxiliar no contexto, promovendo um ambiente de colaboração.

Conforme observado, com base na categorização realizada, balizada em Triguero et al. (2013), Cheng e Shiu (2012) e Gavronski et al. (2012) conseguiu-se chegar a uma associação com a gestão do conhecimento, pela interligação com os aspectos de aquisição de conhecimento, denotando deste modo, uma série de delineamentos que apoiam a análise, concedendo simultaneamente veracidade a mesma, e demonstrando que a associação é pertinente, podendo agregar valor às operações sustentáveis ao considerar a incorporação da inovação no âmbito das operações ambientais, e ainda, ao reconhecer que a aprendizagem e a gestão do conhecimento apresentam uma virtuosa ligação entre si, a qual é necessária para que as implementações possam ocorrer, e para que a transferência e o compartilhamento de conhecimento para as atividades possa de fato ser configurado, acarretando em uma colaboração em rede, característica fundamental para este tipo de criação.

Deste modo, consoante a categorização realizada, associada a coleta de dados, tornouse possível inferir que, as atividades relativas aos projetos relacionadas aos processos de manufatura, ou que remetem ao desempenho de processos específicos, à sua otimização, ou à recuperação de seus efluentes, podem vir a ser auxiliadas com vitalidade pela gestão do conhecimento na forma de práticas que possibilitem a identificação de oportunidades, como o benchmarking; que permitam a identificação de métodos, procedimentos ou novos aperfeiçoamentos que possam ser utilizados, como as melhores práticas; ou por bancos de dados que forneçam informações acerca de condutas já desenvolvidas e suas conclusões, como as lições aprendidas.

Nesta mesma trajetória, por outro lado, as atividades dos projetos relacionadas à identificação e elucidação de requisitos para um determinado procedimento, ou a busca por conhecimentos práticos sui generis, que se evidenciam na prospecção por novos conhecimentos que sejam capazes de tornar mais fáceis e mais simples alguns aspectos relativos à fabricação de um novo produto, ou à melhoria de um já existente (i.e. acondicionamento, decomposição de materiais, conservação de energia, etc), podem vir a ser auxiliadas com vitalidade pela gestão do conhecimento na forma de práticas que permitam tanto a acessibilidade a dados institucionais, quanto a disseminação de novos conhecimentos, como os portais corporativos; por bases de dados que permitam o acesso à técnicas, processos e expertise, como a memória corporativa, ou por ambientes que possibilitem a troca de conhecimentos singulares e específicos, como as comunidades de prática.

Os resultados da pesquisa devem também ser analisados à luz de suas limitações ou contribuições para pesquisas futuras. Este trabalho limitou-se a um estudo de caso, no entanto, seus resultados apontam para uma necessidade de maior aprofundamento, requerendo assim, uma ampliação dos casos, com maior de empresas investigadas, e simultaneamente, a aplicação em campo, das práticas de gestão do conhecimento no contexto dos projetos de ecoinovação.

Perspectivas em Gestão \& Conhecimento, João Pessoa, v. 9, n. 1, p. 42-61, jan./abr. 2019. 
Os resultados da pesquisa sugerem ainda, uma maior investigação acerca do papel dos gestores, devido a relevância assumida para a geração em eco-processos. De igual importância, outra contribuição possível para futuras pesquisas, é a junção entre as fases de pesquisa, produção e uso em projetos que envolvam a geração de ecoinovações em processo, devido a relevância dos processos de conhecimento nestes projetos.

\section{REFERÊNCIAS}

ANDERSEN, M. M. Eco-innovation- towards a taxonomy and a theory. Druid Conference. Entrepreneurship and innovation, june, 17-20, 2008.

ARMBRECHT JR, F. M Ross et al. Knowledge management in research and development. Research Technology Management, p. 28-48, 2001.

ARUNDEL, A., KEMP, R. Measuring Eco-Innovation. UNU-MERIT Research Memorandum, 017, 2009.

BEISE, M.; RENNINGS. K. Lead markets and regulation: a framework for analyzing the international diffusion of environmental. Ecological Economics, v.52, n.1, p. 5-17, 2005.

BELIN, J.; HORBACH, J.; OLTRA, V. Determinants and specificities of eco-innovations - An econometric analysis for France and Germany based on the Community Innovation Survey. DIME - Dynamics of Institutions and Markets in Europe, working paper $\mathrm{n}$. 10, 2009.

BOCKEN, N. M. P.; FARRACHO, M.; BOSWORTH, R.; KEMP, R. The front-end of eco-innovation of eco-innovative small and medium sized companies. Journal of Engineering and Technology Management. 31, 43-57, 2014.

BRÄNNBACK, M. R \& D collaboration: role of Ba in knowledge-creating networks. Knowledge Management Research \& Practice, v. 1, p. 28-38, 2003.

CAINELLI, G.; MAZZANTI, M.; MONTRESOR, S. Environmental innovations, local networks and internationalization. Working Paper 8/2011 OPENLOC. University of Trento, Italy, 2011.

CASTIAUX, A. Developing Dynamic Capabilities to meet sustainable development challenges. International Journal of Innovation Management, v. 16, n. 6, 16 p., 2012.

CHENG, C.; E. SHIU. Validation of a proposed instrument for measuring eco-innovation: An implementation perspective. Technovation, v. 32,'p. 329-344, 2012.

DEMIREL, P.; KESIDOU, E. Stimulating differents types of eco-innovation in the UK: Government policies and firm motivations. Ecological Economics, v. 70, n. 8, p. 1546-1558, 2011.

ELMQUIST, M., SEGRESTIN, B. Sustainable development through innovative design: lessons from the KCP method experimented with an automotive firm. Int. J. Automotive Technology and Management, v. 9, n. 2, p. 229-244, 2009. 
GAVRONSKI, I., KLASSEN, R. D., VACHON, S., NASCIMENTO, L. F. M. do. (2012) A learning and knowledge approach to sustainable operations. International Journal of Production Economics, v. 140, n. 1, p. 183-192, 2012.

HELLSTRÖM, T. Dimensions of Environmentally Sustainable Innovation: the Structure of Ecoinnovation Concepts. Sustainable Development, v. 15, p. 148-159, 2007.

HUANG, Y.-C.; WU, Y. C. J. The effects of organizational factors on green new product success: Evidence from high-tech industries in Taiwan. Management Decision, v. 48, n. 10, p. 15391567, 2010.

JONES, E.; HARRISON, D.; MCLAREN, J. Managing Creative Eco-innovation. Structuring outputs from Eco-innovation projects. The Journal of Sustainable Product Design, v. 1, p. 27-39, 2001.

KEMP, R; PEARSON, P. (Eds). Final report of the project Measuring Eco-Innovation; Maastricht, 113 p., 2008.

KHURANA, A.; ROSENTHAL, S. R. Integrating the fuzzy front end of new product development. Sloan Management Review, v. 38, n. 2, p. 103-120, 1997.

KHURANA, A.; ROSENTHAL, S. R. Towards holistic "front ends" in new product development. Journal of Product Innovation Management, v. 15, n. 1, p. 57-74, 1998.

KLEEF, J. A. G. van; ROOME, N. J. Developing capabilities and competence for sustainable business management as innovation: a research agenda. Journal of Cleaner Production, v. 15, n. 1, p. 38-51, 2007.

KUNIYOSHI, M. S. Institucionalização da gestão do conhecimento: um estudo das práticas gerenciais e suas contribuições para o poder de competição das empresas do setor elétricoeletrônico. 2008. Tese de Doutorado. Universidade de São Paulo, 2008.

LENOX, M., EHRENFELD, J. Organizing for effective environmental design. Business Strategy and the environment, v. 6, p. 187-196, 1997.

MAÇANEIRO, M.B., CUNHA, S. K. da. Eco-Inovação: um quadro de referências para pesquisas futuras. Anpad, 2010.

MALMBORG, F. von. Stimulating learning and innovation in networks for regional sustainable development: the role of local authorities. Journal of Cleaner Production, v. 15, n. 17, p. 17301741, 2007.

NONAKA, I. The knowledge-creating company. Harvard Business Review, 1991.

NONAKA, I.; TAKEUCHI, H. Criação de conhecimento na empresa. Tradução Ana Beatriz Rodrigues. 13. ed. Rio de Janeiro: Elsevier, 1997.

NONAKA, I., KONNO, N. The Concept of "Ba': Building Foundation for Knowledge Creation. California Management Review, 40, 3. Spring, 1998.

OECD. Eco-Innovation in industry: Enabling Green Growth, 2009a. 
OECD. Sustainable Manufacturing and Eco-Innovation: Framework, Practices and Measurement- Synthesis Report, 2009b.

O'HARE, J. et al. Eco-innovation Manual. Draft version 1.0. UNEP/ European Comission, 2014a.

O'HARE, J. et al. Eco-innovation Manual. Tools Instructions. Draft version 1.0. UNEP/ European Comission, 2014b.

OMETTO, A. R.; PERES, R. B.; SAAVEDRA, Y. M. B. Ecoinovação para a melhoria de produtos e serviços: experiências espanholas e brasileiras nos setores industrial, urbano e agrícola, São Carlos- Diagrama Editorial, 2012.

PORTER, M. E.; LINDE, C. Toward a new conception of the environment-competitiveness relationship. Journal of economic perspectives, v. 9, n. 4, p. 97-118, 1995.

PUJARI, D. Eco-innovation and new product development: understanding the influences on market performance. Technovation, v. 26, n. 1, p. 76-85, 2006.

REID, A; MIEDZINSKI, M. Eco-innovation. Final Report for sectoral innovation watch, 2008.

TRIGUERO, A.; MORENO-MONDÉJAR, L.; DAVIA, M.A. Drivers of different types of ecoinnovation in European SMEs. Ecological Economics, v. 92, p. 25-33, 2013.

WAGNER, M. Innovation and Competitive advantages from the integration of Strategic aspects with social and environmental management in European firms. Business Strategy and the environment, v. 18, p. 291-306, 2009.

WONG, S. K.S. Environmental requirements, Knowledge sharing and Green Innovation: Empirical Evidence from the Electronics Industry in China. Business Strategy and the Environment, v. 22, p. 321-338, 2013. 